\title{
Pharmacokinetic Studies of an In Situ Forming Gel System for Controlled Delivery of Enrofloxacin In Pigs
}

\author{
Zugong $\mathrm{Yu}^{1}{ }^{*}$, Huimin $\mathrm{Li}^{1}$, Yue Xiong ${ }^{2}$, Fanxi Guo ${ }^{1}$ and Zhenrui Zhang ${ }^{1}$ \\ ${ }^{1}$ Laboratory of Veterinary Pharmacology and Toxicology, College of Veterinary Medicine, Nanjing Agricultural University, Nanjing, Jiangsu Province, \\ China \\ ${ }^{2}$ Animal Products Quality Inspection and Test Center in Jiangsu Province, Nanjing 210036, China
}

Received: October 16, 2017; Accepted: January 24, 2018; Published: January 26, 2018

*Corresponding author: Zugong Yu, College of Veterinary Medicine, Nanjing Agricultural University, 1 Wei Gang Road, Nanjing, Jiangsu Province, 210095 China, Tel: +86-025-84396770; Fax: +86-025-84398669; Email: yuzugong@njau.edu.cn

\begin{abstract}
The objective of this study was to evaluate the pharmacokinetic characteristics of enrofloxacin (ENR) in situ forming gel in pigs following a single intramuscular administration. Twelve healthy pigs were randomly divided into two groups ( 6 pigs per group), then administered $20 \mathrm{mg} / \mathrm{kg}$ body weight (b.w.) ENR in situ forming gel and $5 \mathrm{mg} / \mathrm{kg}$ b.w. ENR conventional injection respectively. Highperformance liquid chromatography was used to determine ENR plasma concentrations. The important pharmacokinetic parameters of ENR in situ forming gel and conventional injection in pigs were as follows: MRT (mean residence time) $49.39 \pm 8.97 \mathrm{~h}$ verse $11.75 \pm 0.90$ $\mathrm{h}, \mathrm{C}_{\max }$ (maximal concentration) $1.71 \pm 0.24 \mu \mathrm{g} / \mathrm{mL}$ verse $1.76 \pm 0.32$ $\mu \mathrm{g} / \mathrm{mL}, \mathrm{t}_{1 / 2 \lambda z}$ (terminal elimination half-life) $42.92 \pm 9.80 \mathrm{~h}$ verse 9.17 $\pm 0.61 \mathrm{~h}$. Results suggest that the $\mathrm{C}_{\max }$ of ENR in situ forming gel was in the range of ideal bactericidal concentration, and values of $t_{1 / 2 \lambda z}$ and MRT were greatly extended, which could maintain the effective blood drug concentrations for a long time. Therefore, the pharmacokinetic characteristics of ENR in situ forming gel in pigs following a single i.m. administration were ideal. And the in situ forming gel system seems to be a feasible approach for ENR long-acting delivery.
\end{abstract}

Keywords: Enrofloxacin; Sustained delivery; In situ forming gel; Pharmacokinetic; Pigs

\section{Introduction}

Enrofloxacin (ENR), a synthetic agent of fluoroquinolone developed specifically for veterinary use, exhibits a broad spectrum of antibacterial activity [13]. It is active at low concentrations, compared with other classes of antimicrobial agents $[14,22]$. Similar to other fluoroquinolones, ENR produce their bactericidal properties by inhibiting the type IIA topoisomerase (DNA gyrase/topoisomerase II and topoisomerase IV), thereby preventing supercoiling and synthesis of bacterial DNA [9]. Due to the excellent antibacterial scope and activity, this kind of drugs has been widely applied in veterinary clinical since the date of listing.

Studies on the in vivo process of ENR conventional injection in animals showed that it had good absorption and high drug concentrations within the organism by injection, then it's suitable for treatment and prevention of bacterial infection in tissues $[6,10,15,36]$. But the terminal elimination half-life $\left(t_{1 / 2 \lambda z}\right)$ in pigs was less than $9 \sim 12 \mathrm{~h}$ after i.m. (intramuscular) or s.c. (subcutaneous) injection $[1,2,27,31,35]$ Thereby, the recommended dosing regimen of ENR conventional injection was administrated a single $2.5 \sim 5 \mathrm{mg} / \mathrm{kg}$ b.w. per day or twice a day, meaning that a course of treatment needs multiple dosing [40]. Obviously, in the clinical application the conventional injection caused a lot of inconvenience, for example, repeated stress response maybe worsen animals' illness or result in more disease, and the drugs' action was not sufficient when it was in peaks and valleys, what's more, frequency administration spent great human, financial and material resources.

On the other hand, studies revealed that the fluoroquinolones had biphasic concentration-dependent characteristics. When the blood drug concentrations were far more than the MIC (minimum inhibition concentration), they didn't have the killing effect, only had bacteriostatic action [4]. Then the drugs' action could not be exerted sufficiently. It also brings new challenges to the development of long-acting injection of this drug. The preparation methods of traditional long-acting injection, such as the process for making suspension or oil, were to increase blood drug concentration by adding the dose, which maybe also play against the drug's efficacy. For these reasons, there is a need for at least drug administration as possible, followed by longer duration of therapeutically effective drug concentration in the body.

Injectable in situ forming systems have received considerable interest over the past few years, which had many distinct advantages including simple operation, low cost, and easy industrialized production $[8,20,21,24,30]$. The reversal thermal gelation (RTG) phenomenon constitutes one of the most promising strategies for the development of injectable drug delivery systems. The poloxamer 407 (P407) thermosensible in situ gels display low viscosity at ambient temperature, allowing the gel to flow freely into the body through a syringe during injection, and exhibit a sharp viscosity increase following a certain temperature rise, producing a semi-solid gel as the drug ' deposit ' at body temperature $[25,33]$. Drugs release slow along with the gel to achieve the purpose of sustained-release. The in vitro process of thermo sensible in situ gel form of many drugs indicated that the release of this drug could sustain $4 \sim 7$ days $[23,28,29]$, which highly accorded with the medication cycle $(3 \sim$ 5 days) in veterinary clinical application. 
To avoid the disadvantages of the ENR conventional injection, we developed a thermo sensible in situ forming gel with moderate poloxamers (P407 and P188) for ENR, which have the advantage of being injected as a liquid that changes into a solid gel immediately after injection. Through repeated experiments, we achieved that the gelation temperatures of the form we developed were $34 \pm 0.5^{\circ} \mathrm{C}$, and the gelation times were $7.5 \pm 0.5 \mathrm{~s}$ in $37^{\circ} \mathrm{C}$, in vitro release was about $40.7 \%$ in $24 \mathrm{~h}$, and followed by sustained release was up to $100 \%$ within $144 \mathrm{~h}$, which confirmed that the in vitro release of this form was good. Therefore, the objectives of this study were to evaluate pharmacokinetic characteristics of this form in pigs following a single IM administration, and then promote the use of it in veterinary clinical treatment and prevention.

\section{Materials and methods}

\section{Drugs and reagents}

98.5\% (w/v) ENR was purchased from Guobang Pharmaceutical Corporation (Zhejiang, China). 99.9\% (w/v) ENR analytical standards (Batch number, H0081206) were purchased from the China Institute of Veterinary Drug Control (Beijing, China). 5\% (w/v) ENR injection was purchased from Hengtong Animal Pharmacy (Sichuan, China). 20\% (w/v) ENR injectable in situ forming gel (Gelation temperatures, $33.5 \sim 34.5^{\circ} \mathrm{C}$ ) was homemade with moderate poloxamers (P407 and P188). Acetonitrile was of high-performance liquid chromatography grade and purchased from Merck Corporation (Darmstadt, Germany). All other reagents used for extraction and analysis were analytical reagent grade or better and were commercially available.

\section{Animals}

Pharmacokinetics evaluation was performed on twelve clinically-healthy crossbred pigs (Duroc $\times$ Landrace $\times$ Yorkshire) weighing $10 \pm 1.6 \mathrm{~kg}$. In this trial, they were housed in semicontained pens with access to water ad libitum and a commercial non-medicated chow at scheduled times. Pigs enrolled in the studies had no previous administration to any antibiotic and no drugs were given to the animals during the acclimation or experimental periods. All experimental procedures involving animals were conducted following the guidelines of Nanjing Agricultural University (Nanjing, China) Animal Ethics Committee.

\section{Experimental design}

When pigs were housed in experiment condition for a week of environmental adaptation, they were randomly divided into two groups (6 pigs per group, half mare and half female). Prior to ENR administration, all pigs were weighed and blood samples were taken from the precaval vein for control. For group one, each pig was administered a single i.m. injection in gluteal of $20 \mathrm{mg} / \mathrm{kg}$ b.w. ENR in situ forming gel and blood samples were collected from the precaval vein of each pig and collected in tubes containing heparin as anticoagulant at $0.25,0.5,2,5,9,12,24,36$, $48,60,72,96,120,144,168$ and $180 \mathrm{~h}$ after dosing. For the other group, each pig was administered a single i.m. injection in gluteal of $5 \mathrm{mg} / \mathrm{kg}$ b.w. ENR conventional injection and blood samples were taken from the precaval vein of each pig and collected in tubes with anticoagulant (heparin) at $0.25,0.5,2,5,9,12,24,36$, $48,60,72,84$ and $96 \mathrm{~h}$ after dosing. Samples were centrifuged within $1 \mathrm{~h}$ after collection and plasma samples were stored frozen $\left(-20^{\circ} \mathrm{C}\right)$ until analysis. All the samples were analyzed within one week after the experiments.

\section{Analytical method}

Apparatus conditions: The HPLC system (Agilent 1200 series; Agilent Technologies Co. Ltd., Palo Alto, Santa Clara, CA, USA) comprised a G1311A quaternary pump, a G1328B MAN injector, a G1314B UV detector, a G1316A column heater and online/offline analysis software. The UV detector was set to monitor $278 \mathrm{~nm}$. Chromatographic separations were performed on Eclipse XDB-C18 column $(5-\mu \mathrm{m}, 250 \times 4.6 \mathrm{~mm})$. The column temperature was maintained at $35^{\circ} \mathrm{C}$. The composition of the mobile phase was phosphoric acid (adjust pH to 3.5 with triethylamine; $0.1 \mathrm{M})$-acetonitrile $(84: 16, \mathrm{v} / \mathrm{v})$. The flow rate of the mobile phase was set to $0.8 \mathrm{~mL} / \mathrm{min}$.

Sample preparation: The extraction method was performed as described by Guo M [18] with some modifications. Briefly, the frozen plasma samples $(0.2 \mathrm{~mL})$ were thawed at room temperature and added $2 \mathrm{~mL}$ of methylene chloride. The mixture was mechanically shaken for $3 \mathrm{~min}$ and centrifuged for $10 \mathrm{~min}$ at $8000 \times g$, and then the lower layer was manually transferred into a tube. Then the organic layer was evaporated at $50^{\circ} \mathrm{C}$ under nitrogen and the residue was reconstituted in $0.2 \mathrm{~mL}$ of mobile phase. At last, the samples were vortex mixed for $5 \mathrm{~min}$, centrifuged at $12000 \times g$ for $10 \mathrm{~min}$ and $20 \mu \mathrm{L}$ volumes was injected into HPLC system.

\section{Pharmacokinetic data analysis}

ENR plasma concentration verse time date of each animal was subjected to the non-compartmental analysis (NCA) using the computer program WinNonlin version 5.2 (Pharsight, CA, USA). Lambda $\mathrm{z}$ is a first-order rate constant associated with the terminal (log linear) segment of the curve. It was estimated by the linear regression of the terminal data points. The terminal elimination half-life $\left(\mathrm{t}_{1 / 2 \lambda z}\right)$ was calculated by $\mathrm{t}_{1 / 2 \lambda z}=0.693 / \lambda \mathrm{z}$. Areas under the plasma concentration-time curves AUC $_{0 \rightarrow \infty}$ and $\mathrm{AUC}_{0 \rightarrow t}$ ) were calculated by the method of trapezoids. Peak plasma concentrations $\left(\mathrm{C}_{\max }\right)$ of drug and times to reach peak concentration $\left(\mathrm{t}_{\max }\right)$ were determined from the individual plasma concentration-time curves.

\section{Statistical analysis}

All data were presented as mean \pm standard deviation (SD). The pharmacokinetic parameters determined were compared by one-way analysis of variance using statistical software (SPSS version 12; SPSS Inc., Chicago, IL, USA). In all cases, $\mathrm{p}<0.05$ was considered statistically significant.

\section{Results}

No adverse reaction or apparent sign of toxic effects related to ENR were observed in the days following injection. The serum concentration vs. time data of ENR injectable in situ forming 
gel formulation and conventional injection following single i.m. administration and the pharmacokinetic parameters are presented in Figure and Table, respectively.

In this study, blood concentrations of ENR in situ forming gel were monitored over $180 \mathrm{~h}$ while the conventional injections were just $72 \mathrm{~h}$. There were significant differences $(\mathrm{p}<0.01)$ between ENR in situ forming gel and conventional injection in pharmacokinetic parameters $\mathrm{t}_{1 / 2 \lambda z}$. The terminal elimination halflife calculated for ENR in situ gel $42.92 \pm 9.80 \mathrm{~h}$ was significantly higher than that of the conventional injection which was $9.17 \pm$ $0.61 \mathrm{~h}$. The area under the blood concentration vs. time curve (AUC) of ENR in situ gel was $48.00 \pm 6.44 \mu \mathrm{g} \cdot \mathrm{h} / \mathrm{mL}$, obtained

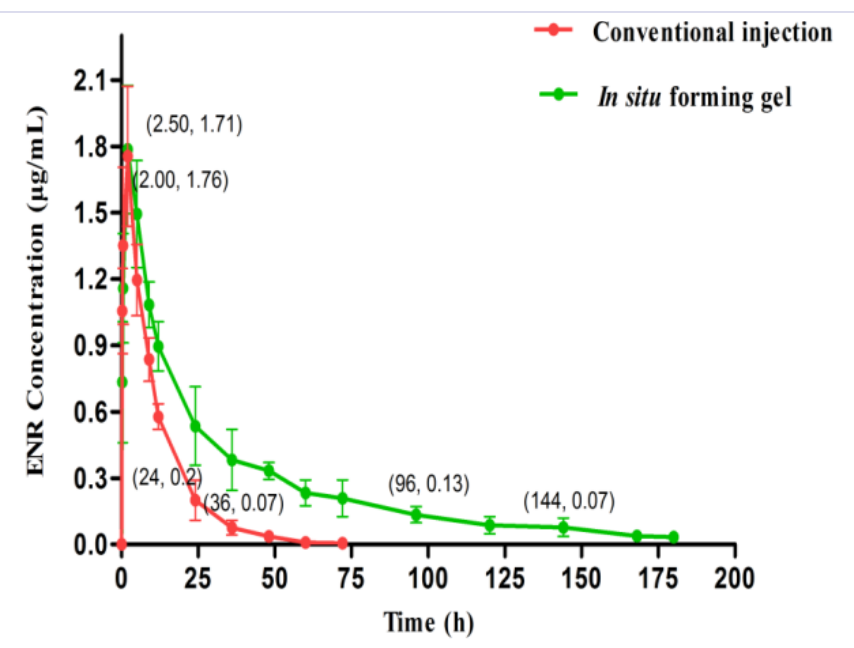

Figure 1: Plasma concentration-time profile of ENR in situ forming gel in pigs following i.m. administration of $20 \mathrm{mg} / \mathrm{kg}$ b.w. and conventional injection in pigs following i.m. administration of $5 \mathrm{mg} / \mathrm{kg}$ b.w. (mean \pm $\mathrm{SD}, \mathrm{n}=6)$.

Table 1: Pharmacokinetic parameters of ENR in situ forming gel (20 $\mathrm{mg} / \mathrm{kg}$ b.w.) and conventional injection ( $5 \mathrm{mg} / \mathrm{kg}$ b.w.) in pigs $(\mathrm{n}=6)$ following i.m. administration

Value for indicated group

\begin{tabular}{|c|c|c|}
\hline Parameters & $\begin{array}{l}\text { Conventional } \\
\text { injection }\end{array}$ & In situ forming gel \\
\hline MRT (h) & $11.75 \pm 0.90$ & $49.39 \pm 8.97$ \\
\hline $\mathrm{C}_{\max }(\mu \mathrm{g} / \mathrm{mL})$ & $1.76 \pm 0.32$ & $1.71 \pm 0.24$ \\
\hline $\mathrm{t}_{\max }(\mathrm{h})$ & $2.00 \pm 0.00$ & $2.50 \pm 1.22$ \\
\hline $\mathrm{t}_{1 / 2 \lambda z}(\mathrm{~h})$ & $9.17 \pm 0.61$ & $42.92 \pm 9.80 * *$ \\
\hline $\mathrm{AUC}_{0 \rightarrow \mathrm{t}}(\mu \mathrm{g} \cdot \mathrm{h} / \mathrm{mL})$ & $19.96 \pm 4.07$ & $48.00 \pm 6.44$ \\
\hline $\operatorname{AUC}_{0 \rightarrow \infty}(\mu \mathrm{g} \cdot \mathrm{h} / \mathrm{mL})$ & $20.12 \pm 3.97$ & $49.86 \pm 5.59$ \\
\hline \multicolumn{3}{|c|}{$\begin{array}{l}{ }^{* *} \mathrm{P}<0.01 \text {. MRT: mean residence time, } \mathrm{C}_{\text {max }}: \text { maximal concentration, } \mathrm{t}_{\text {max }} \\
\text { time needed to reach } \mathrm{C}_{\text {max }}, \mathrm{t}_{1 / 2 \lambda z}: \text { terminal elimination half-life, AUC: area } \\
\text { under the blood concentration vs. time curve. Data are presented as } \\
\text { mean } \pm \mathrm{SD} \text {. } \\
\text { There were significant differences }(\mathrm{p}<0.01) \text { between ENR in situ forming } \\
\text { gel and conventional injection, in pharmacokinetic parameters } \mathrm{t}_{1 / 2 \lambda z} \text {. As } \\
\text { the doses between ENR in situ forming gel and conventional injection are } \\
\text { different, the significance analysis of the parameters MRT, } \mathrm{C}_{\max }, \mathrm{t}_{\max } \text { and } \\
\text { AUC which are positive correlated with dose is meaningless. }\end{array}$} \\
\hline
\end{tabular}

for hours 0 to 180 by the trapezoid rule and normalized for injected dose, while that of conventional one was $19.96 \pm 4.07$ $\mu \mathrm{g} \cdot \mathrm{h} / \mathrm{mL}$. The mean residence time (MRT) of ENR in situ gel and conventional injection were $49.39 \pm 8.97 \mathrm{~h}$ and $11.75 \pm 0.90 \mathrm{~h}$, respectively. The $\mathrm{C}_{\max }$ value of ENR injectable in situ forming gel had a similar level with the conventional injection, which was 1.71 $\pm 0.24 \mu \mathrm{g} / \mathrm{mL}$ reached after $2.50 \pm 1.22 \mathrm{~h}$ while the conventional injection was $1.76 \pm 0.32 \mu \mathrm{g} / \mathrm{mL}$ reached after $2.00 \pm 0.00 \mathrm{~h}$.

\section{Discussion}

In our study, a novel approach based on thermoreversible in situ forming gel with poloxamers for prolonged release of ENR had been implemented. The in vivo pharmacokinetic results showed that the mean residence time (MRT) and the terminal elimination half-life $\left(\mathrm{t}_{1 / 2 \lambda \mathrm{z}}\right)$ of the drugs we developed were respectively $49.39 \pm 8.97 \mathrm{~h}$ and $42.92 \pm 9.80 \mathrm{~h}$ after a single 20 $\mathrm{mg} / \mathrm{kg}$ b.w. i.m. injection. Significantly, the in vivo characteristics of ENR thermoreversible in situ forming gel we developed in pigs were superior to that of the ENR conventional injection [2, 27], and also more ideal than the reported results of ENR sustainedrelease injection [37, 39]. Studies have been conducted on the pharmacokinetics of different ENR forms after different dose under different injection route extensively. For example, Zeng et al. (2002) [39] found that the $t_{1 / 2 \lambda z}$ value of ENR suspension in pigs was $18.95 \mathrm{~h}$ after a single $10 \mathrm{mg} / \mathrm{kg}$ b.w. i.m. injection; Messenger et al. (2011) [26] reported after a single $7.5 \mathrm{mg} / \mathrm{kg}$ b.w. s.c. injection , the $t_{1 / 2 \lambda z}$ value of ENR (Baytril 100) in pigs was $26.6 \mathrm{~h}$; Xiao et al. (2002) [37] found that at the dose of $18.75 \mathrm{mg} /$ $\mathrm{kg}$ b.w. under i.m. injection, the $t_{1 / 2 \lambda z}$ value of ENR long-acting injection solution was $19.47 \mathrm{~h}$, and so on. Though all these dosing regimens $\left(\mathrm{t}_{1 / 2 \lambda z}, 18.95 \sim 26.6 \mathrm{~h}\right)$ have improved compare to the recommended $\left(\mathrm{t}_{1 / 2 \lambda z^{\prime}}, 9 \sim 12 \mathrm{~h}\right)$, the $\mathrm{t}_{1 / 2 \lambda z}$ value is still further lower than that of ENR long-acting forms in our study $\left(\mathrm{t}_{1 / 2 \lambda z}=42.92 \mathrm{~h}\right)$.

Due to the addition of poloxamer 407 (P407), thermosensible in situ gel system has the reversal thermal characteristics, and addition of proper poloxamer 188 (P188) could adjust its gelation temperatures $[7,12,38]$. The preparation of this kind of thermosensible in situ gel often adopts the " Cold method " [34], which is fully equipped with the feasibility of industrial production. In medicine, multiple related preparations are in the process of new drug application (NDA). Some other additives, such as carboxymethylcellulose sodium (CMC-Na), polyvinylpyrrolidone (PVP), carbomer, and even sodium chloride $(\mathrm{NaCl})$, can affect the gelation strength and gelation time of thermosensible in situ gel. Because the patent of this drug is in the examination period, it is inconvenient to discuss its formula in this paper. But the results indicated that this prescription composition was ideal.

The characteristics of antibacterial activity of the fluoroquinolones and the relationship between the MIC and the blood drug concentration have been in-depth study [4]. As the ratio of fluoroquinolones concentration to MIC increases from 1:1 to the optimal bactericidal concentration (usually 10:1), the fluoroquinolones presents concentration-dependent killing effect. The concentration-dependent killing effect may plateau off when the ratio of fluoroquinolones concentration to MIC reaches 
15:1 to $20: 1$ and at ratios greater than 20:1 the fluoroquinolones may become bacteriostatic. The MIC of ENR for the pathogens of common infectious diseases in clinical is $0.001 \sim 0.1 \mu \mathrm{g} / \mathrm{mL}$ [32]. One of the characteristics of ENR is that the MIC for sensitive bacteria is low. For example, the MIC values of ENR for swine pathogenic escherichia coli and erysipelas coli respectively are 0.05 and $0.1 \mu \mathrm{g} / \mathrm{mL}$; for swine actinobacillus pleuropneumoniae, the $\mathrm{MIC}_{90}$ is no more than $0.06 \mu \mathrm{g} / \mathrm{mL}$; for swine actinobacillus, escherichia coli, salmonella krefeld, klebsiella pneumonia, pasteurella multocida isolated in clinical, the $\mathrm{MIC}_{90}$ values are lower than $0.128 \mu \mathrm{g} / \mathrm{mL}[3,5]$.

In our study, the mean plasma concentration following the injection of in situ gel in pigs was $0.13 \mu \mathrm{g} / \mathrm{mL}$ at $96 \mathrm{~h}, 0.07 \mu \mathrm{g} / \mathrm{mL}$ at $144 \mathrm{~h}$, indicating that the drugs we developed had much longer acting time than common injection. In spite of the dosage of ENR in situ gel was four times as large as that of ENR conventional injection; the $\mathrm{C}_{\max }$ of them had a similar level. And the $\mathrm{C}_{\max } / \mathrm{MIC}$ ratio of ENR in situ gel was less than 20, thus avoiding excessive concentration result in bacteriostatic. This can be explained with the higher distribution volume that leads to lower peak plasma levels within the pigs. Therefore, when compared with the control injection, the in situ gel can lead to a reduction of the severity of systemic side effects induced by ENR. Furthermore, to maximize clinical efficacy and reduce selection of resistant bacteria, $\mathrm{C}_{\max } / \mathrm{MIC}$ ratio $\geq 10: 1$ or $\mathrm{AUC} / \mathrm{MIC}_{90}$ ratio $\geq 125: 1$ may be required $[11,16,17,19]$. In our study, the AUC of ENR in situ gel in pigs which was $48.00 \pm 6.44 \mu \mathrm{g} \cdot \mathrm{h} / \mathrm{mL}$ at a single $20 \mu \mathrm{g} / \mathrm{mL}$ b.w. dose. Obviously, the AUC/MIC ${ }_{90}$ ratio of ENR in situ gel was more than 125, suggesting that the ENR in situ gel had a better clinical efficacy.

\section{Conclusion}

The $\mathrm{C}_{\max }$ of ENR in situ gel was in the range of ideal bactericidal concentration, and the values of $t_{1 / 2 \lambda z}$ and MRT were greatly extended, which could maintain the effective blood drug concentrations for a long time. Therefore, following a single i.m. administration, the pharmacokinetic characteristics of ENR in situ gel in pigs were ideal. On the other hand, the ratios of $\mathrm{C}_{\max } /$ MIC and AUC/MIC ${ }_{90}$ suggested that the ENR in situ gel had a better clinical efficacy. According to this reasonable formulation design, it is worth popularizing in clinical application.

\section{Acknowledgments}

This study was supported by the Priority Academic Program Development of Jiangsu Higher Education Institution (PAPD).

\section{References}

1. Elmas M, Uney K, Yazar E, Karabacak A, Tras B. Pharmacokinetics of enrofloxacin following intravenous and intramuscular administration in Angora rabbits. Res Vet Sci. 2007;82(2):242-245.

2. Elsheikh HA, Taha AAW, Khalafallah AI, Osman IAM. Disposition kinetics of enrofloxacin (Baytril 5\%) in sheep and goats following intravenous and intramuscular injection using a microbiological assay. Res Vet Sci. 2002;73(2):125-129.

3. Langston VC, Sedrish S, Boothe DM. Disposition of single-dose oral enrofloxacin in the horse. J Vet Pharmacol Ther. 1996;19(4): 316-319.
4. Daniels JB, Tracy G, Irom SJ, Lakritz J. Fluoroquinolone levels in healthy dog urine following a $20-\mathrm{mg} / \mathrm{kg}$ oral dose of enrofloxacin exceed mutant prevention concentration targets against Escherichia coli isolated from canine urinary tract infections. J Vet Pharmacol Ther. 2014;37(2):201-204. doi: 10.1111/jvp.12069

5. Cabanes A, Arboix M, Garcia Anton JM, Reig F. Pharmacokinetics of enrofloxacin after intravenous and intramuscular injection in rabbits. Am J Vet Res. 1992;53(11):2090-2093.

6. Davis JL, Foster DM, Papich MG. Pharmacokinetics and tissue distribution of enrofloxacin and its active metabolite ciprofloxacin in calves. J Vet Pharmacol Ther. 2007;30(6):564-571.

7. Felt S, Papich MG, Howard A, Long T, McKeon G, Torreilles S, et al. Tissue distribution of enrofloxacin in African clawed frogs (Xenopus laevis) after intramuscular and subcutaneous administration. J Am Assoc Lab Anim Sci. 2013;52(2):186-188.

8. Wu G, Meng Y, Zhu X, Huang C. Pharmacokinetics and tissue distribution of enrofloxacin and its metabolite ciprofloxacin in the Chinese mittenhanded crab, Eriocheir sinensis. Anal Biochem. 2006;358(1):25-30.

9. Anadon A, Martinez-Larranaga MR, Diaz MJ, Fernandez-Cruz ML, Martinez MA, Frejo MT, et al. Pharmacokinetic variables and tissue residues of enrofloxacin and ciprofloxacin in healthy pigs. Am J Vet Res. 1999;60(11):1377-1382.

10. Bimazubute M, Cambier C, Baert K, Vanbelle S, Chiap P, Albert A, et al. Penetration of enrofloxacin into the nasal secretions and relationship between nasal secretions and plasma enrofloxacin concentrations after intramuscular administration in healthy pigs. J Vet Pharmacol Ther. 2010;33(2):183-188. doi: 10.1111/j.1365-2885.2009.01123.x

11. Messenger KM, Papich MG, Blikslager AT. Distribution of enrofloxacin and its active metabolite, using an in vivo ultrafiltration sampling technique after the injection of enrofloxacin to pigs. J Vet Pharmacol Ther. 2012;35(5):452-459. doi: 10.1111/j.1365-2885.2011.01338.x

12. Post LO, Farrell DE, Cope CV, Baker JD, Myers MJ. The effect of endotoxin and dexamethasone on enrofloxacin pharmacokinetic parameters in swine. J Pharmacol Exp Ther. 2003;304(2):889-895.

13. Wiuff C, Lykkesfeldt J, Aarestrup FM, Svendsen O. Distribution of enrofloxacin in intestinal tissue and contents of healthy pigs after oral and intramuscular administrations. J Vet Pharmacol Ther. 2002;25(2): 335-342.

14.Zeng Z. Veterinary Medicine Manual. Chemical Industry Press, Beijing, 2012;115-116: 2ndedition.

15. Brown SA. Fluoroquinolones in animal health. J Vet Pharmacol Ther. 1996;19(1):1-14.

16. Chitkara D, Shikanov A, Kumar N, Domb AJ. Biodegradable injectable in situ depot-forming drug delivery systems. Macromol Biosci. 2006;6(12):977-990.

17. Hatefi A, Amsden B. Biodegradable injectable in situ forming drug delivery systems. J Control Release. 2002;80(1-3):9-28.

18. Kranz H, Yilmaz E, Brazeau GA, Bodmeier R. In vitro and in vivo drug release from a novel in situ forming drug delivery system. Pharm Res. 2008;25(6):1347-1354.

19. Lin X, Yang SS, Gou JX, Zhao MM, Zhang Y, Qi N, et al. A novel risperidoneloaded SAIB-PLGA mixture matrix depot with a reduced burst release: effects of solvents and PLGA on drug release behaviors in vitro/in vivo. J Mater Sci Mater Med. 2012;23(2):443-455. doi: 10.1007/s10856011-4521-2 
20. Packhaeuser CB, Schnieders J, Oster CG, Kissel T. In situ forming parenteral drug delivery systems: an overview. Eur J Pharm Biopharm. 2004;58(2):445-455.

21. Liu Y, Lu WL, Wang HC, Zhang X, Zhang H, Wang XQ, et al. Controlled delivery of recombinant hirudin based on thermo-sensitive Pluronic (R) F127 hydrogel for subcutaneous administration: In vitro and in vivo characterization. J Control Release. 2007;117(3):387-395.

22. Radivojsa M, Grabnar I, Grabnar PA. Thermoreversible in situ gelling poloxamer-based systems with chitosan nanocomplexes for prolonged subcutaneous delivery of heparin: Design and in vitro evaluation. Eur J Pharm Sci. 2013;50(1):93-101. doi: 10.1016/j.ejps.2013.03.002

23. Li J, Liu H, Liu LL, Cai CN, Xin HX, Liu W. Design and Evaluation of a Brinzolamide Drug-Resin in Situ Thermosensitive Gelling System for Sustained Ophthalmic Drug Delivery. Chem Pharm Bull (Tokyo). 2014;62(10):1000-1008.

24. Nie S F, Hsiao W L W, Pan W S, Yang Z J. Thermoreversible Pluronic (R) F127-based hydrogel containing liposomes for the controlled delivery of paclitaxel: in vitro drug release, cell cytotoxicity, and uptake studies. Int J Nanomedicine. 2011;6:151-166. Doi: 10.2147/IJN.S15057

25. Ozguney I, Kardhiqi A, Yildiz G, Ertan G. In vitro-in vivo evaluation of in situ gelling and thermosensitive ketoprofen liquid suppositories. Eur J Drug Metab Pharmacokinet. 2014;39(4): 283-291. Doi: 10.1007/ s13318-013-0157-6

26. Guo M J, Bughio S, Sun Y, Zhang Y, Dong L L, Dai X H, et al. AgeRelated P-Glycoprotein Expression in the Intestine and Affecting the Pharmacokinetics of Orally Administered Enrofloxacin in Broilers. PLoS One. 2013;8(9):e74150. Doi: 10.1371/journal.pone.0074150

27. Xiao T, Yi Y, Liang J, Xiang G, He X, Huang X. Pharmacokinetic studies of enrofloxacin long acting injection in pigs after intramuscular administration. Zhongguo Shou Yao Zazhi. 2002;36(4):21-23.

28.Zeng W, Chen Z, Zeng Z, Feng Q Xia A. The pharmacokinetics and bioavailability of enrofloxacin suspension in pigs. Xu Mu Shou Yi Xue Bao. 2002;33: 63-67. (in Chinese)

29. Messenger K M, Blikslager A T, Papich M G. The Distribution Of Enrofloxacin, And Its Active Metabolite Ciprofloxacin, Using an In-Vivo Ultrafiltration Sampling Technique after the Injection Of Enrofloxacin To Pigs. J Vet Intern Med. 2011;35(5): 452-459. Doi: 10.1111/j.13652885.2011.01338.x
30. Charrueau C, Tuleu C, Astre V, Grossiord J L, Chaumeil J C. Poloxamer 407 as a thermogelling and adhesive polymer for rectal administration of short-chain fatty acids. Drug Dev Ind Pharm. 2001;27(4):351-357. Doi: 10.1081/DDC-100103735

31.El-Kamel A and El-Khatib M. Thermally reversible in situ gelling carbamazepine liquid suppository. Drug Deliv. 2006;13(2):143-148.

32. Yong C S, Yang C H, Rhee J D, Lee B J, Kim D C, Kim D D, et al. Enhanced rectal bioavailability of ibuprofen in rats by poloxamer 188 and menthol. Int J Pharm. 2004;269(1):169-176.

33. Schmolka I R. Artificial skin I. Preparation and properties of pluronic F-127 gels for treatment of burns. J Biomed Mater Res. 1972;6(6):571582. Doi:10.1002/jbm.820060609

34. Prescott J F, Yielding K M. In vitro susceptibility of selected veterinary bacterial pathogens to ciprofloxacin, enrofloxacin and norfloxacin. Can J Vet Res. 1990;54(1):195-197.

35. Boeckh S, Buchanan C, Boeckh A, Wilkie S, Davis C, Buchanan T, et al Pharmacokinetics of the bovine formulation of enrofloxacin (Baytril 100) in horses. Vet Ther. 2001;2(2):129-134.

36. Bugyei K, Black W D, McEwen S. Pharmacokinetics of enrofloxacin given by the oral, intravenous and intramuscular routes in broiler chickens. Can J Vet Res. 1999;63(3):193-200.

37. Drusano G L, Johnson D E, Rosen M, Standiford H C. Pharmacodynamics of a fluoroquinolone antimicrobial agent in a neutropenic rat model of Pseudomonas sepsis. Antimicrob Agents Chemother. 1993;37(3):483490.

38. Forrest A, Nix D E, Ballow C H, Goss T F, Birmingham M C, Schentag $\mathrm{J} J$. Pharmacodynamics of intravenous ciprofloxacin in seriously ill patients. Antimicrob Agents Chemother. 1993;37(5):1073-1081.

39. Gabarda M L, Fernandez-Varon E, Serrano-Rodriguez J M, SerranoCaballero J M, Marin P, Escudero E, et al. Pharmacokinetics And Milk Penetration of a Long-Acting Poloxamer Formulations for Enrofloxacin And Its Metabolite Ciprofloxacin In Lactating Sheep. Basic Clin Pharmacol Toxicol. 2013;113:30-30.

40. Haritova A, Lashev L, Pashov D. Pharmacokinetics of enrofloxacin in lactating sheep. Res Vet Sci. 2003;74(3):241-245. 